\title{
Penerapan Metode Analisa Critical Success Factor PadaSistem Penjualan dan Persediaan Barang
}

\author{
Fifit Alfiah*1 \\ Ana Adiyani ${ }^{2}$ \\ Esa Septiani ${ }^{3}$ \\ ${ }^{1}$ Program Studi Teknik Informatika Fakultas Sains dan Teknologi Universitas Raharja \\ ${ }^{2,3}$ Program Studi Sistem Informasi Fakultas Sains dan Teknologi Universitas Raharja \\ E-mail:*1fifitalfiah@raharja.info, ${ }^{2}$ ana.adiyani@raharja.info, ${ }^{3}$ esa.septiani@raharja.info
}

\begin{abstract}
Abstrak
Pengolahan biji-biji plastik sebagai bahan dasar utama produk-produk plastic dengan keanekaragaman jenis dan ukuran yang saat ini banyak digunakan dalam kehidupan masyarakat sebagai media penyimpanan atau wadah ini tentunya menjadi fokus utama sebagai bahan dasar utama produk plastik yang dijalankan oleh PT. Alsabi Makmuk Plasindo. Dalam proses produksi maupun pengolahan transaksi produk-produk plastic yang di produksi oleh PT. Alsabi ini masih SemiKomputerisasi yaitu menggunakan Ms.Excel sebagai media pengolahan data untuk proses transaksi penjualan dan persediaan produk-produk plasktik, karena pengolahan data transaksi yang masih menggunakan Ms.Excel maka terdapat beberapa kendala antara bagian penjualan dan persediaan barang karena belum terintegrasinya jumlah persediaan barang dengan jumlah barang yang akan di jual. Selain itu penyajian laporan yang kurang akurat juga menjadi bagian kendala dari transaksi penjualan dan persediaan barang dari PT.Alsabi ini menyebabkan membutuhkan waktu kerja yang lama untuk mengintegrasikan data persediaan barang dengan penjualan barang. Berdasarkan permasalahan yang terjadi pada transaksi penjualan dan perssedian produk pada PT. Alsabi maka penulis dalam penelitian skripsi ini membuat sebuah Sistem Informasi berbasis desktop yang menggunakan bahasa pemrograman Ms. Visual FoxPro 9 dengan sistem database berekstensi *.DBF, dan metode pengembangan yang digunakan adalah system development life cycle (SDLC) dan juga metode Analisa yang digunakan adalahCritical Success Factor (CFS) dan hasil dari penelitian ini program sistem informasi sudah selesai 100\% dengan menyesuaikan faktor penentu kesuksesan penjualan dari PT. Alsabi Makmur Plasindo sehingga memudahkan perusahaan dalam proses penjualan dan menentukan persediaan barang berdasarkan penggunaan waktu data dapat diintegrasikan dengan cepat dan baik.
\end{abstract}

Kata Kunci : Penjualan, Persedian barang, Plastik, Critical Success Factor, FoxPro9.

\begin{abstract}
Processing plastic pellets as the main basic material for plastic products with a variety of types and sizes which are currently widely used in people's lives as storage media or containers is of course the main focus as the main basic material for plastic products run by PT. Alsabi Makmuk Plasindo. In the production process and transaction processing of plastic products manufactured by PT. Alsabi is still semi-computerized, namely using Ms. Excel as a data processing medium for the sales transaction process and inventory of plastic products, because transaction data processing is still using Ms. Excel, so there are several obstacles between the sales and inventory department because the number of inventory of goods with the number of goods to be sold. In addition, the inaccurate presentation of reports is also part of the constraints of sales and inventory transactions from PT Alsabi, which causes it to take a long time to integrate inventory data with sales of goods. Based on the problems that occur in sales transactions and product supplies at PT. Alsabi, the writer in this thesis research made a desktop-based information system using Ms. programming language. Visual FoxPro 9 with a database system with the extension *. DBF, and the development method used is the system development life cycle (SDLC) and also the analysis method used is the Critical Success Factor (CFS) and the results of this study the information system program has been completed 100\% with adjusting the determinants of sales success from PT. Alsabi Makmur Plasindo, making it easier for companies in the sales process and determining inventory based on the use of time data can be integrated quickly and well.
\end{abstract}

Keywords: Sales, Supply of goods, Plastics, Critical Success Factor, FoxPro9.

\section{Pendahuluan}

Dalam proses produksi maupun pengolahan transaksi produk-produk plastik yang di produksi oleh PT. Alsabi ini masih Semi-Komputerisasi yaitu menggunakan Ms.Excel sebagai media pengolahan data untuk proses transaksi penjualan dan persediaan produk-produk plasktik, karena pengolahan data transaksi yang masih menggunakan Ms.Excel maka terdapat beberapa kendala antara bagian penjualan dan persediaan barang karena belum terintegrasinya jumlah persediaan barang 
dengan jumlah barang yang akan di jual. Selain itu penyajian laporan yang kurang akurat juga menjadi bagian kendala dari transaksi penjualan dan persediaan barang dari PT.Alsabi ini menyebabkan membutuhkan waktu kerja yang lama untuk mengintegrasikan data persediaan barang dengan penjualan barang[1].

Pemanfaatan CSF dapat meningkatkan keberhasilan pengimplementasian sistem penjualan dan persediaan barang di perusahaan jika CSF digunakan sesuai secara tepat dan efektif agar menghasilkan implementasi sistem yang lebih efisien[2]. Karena transaksi penjualan dan persediaan barang yang ada saat ini masih belum terlaksana dengan baik dalm proses kelola data transaksi penjualan seperti keterangan dari sebuah produk yang dijual, siapa custumer yang melakukan transaksi penjualan maupun data transaksi yang terjadi masih belum terstruktur dan terintegrasi. Sehingga antara persediaan barang dan penjualan harus melakukan pengecekan satu-satu yang mengakibat banyak waktu yang terbuang dan lamanya proses pencatatan, penyimpanan dan pencarian data serta penyajian laporan. Dimana tingkat keberhasilan pengimplementasian sistem penjualan dan persediaan barang yang baik dapat dilihat dari Critical Success Factors (CSFs) dalam pelaksanaannya pada perusahaan[3].

Berdasarkan permasalahan yang telah dipaparkan diatas maka PT. Alsabi Makmur Plasindo ini sangat membutuhkan sistem yang mampu mengolah data penjualan[4] dan persediaan barang dengan cepat, tepat dan akurat yang dapat membantu dalam proses pencatatan, penyimpanan dan pencarian data serta penyajian laporan guna mengambil keputusan yang telah ditentukan dengan merancang sebuah sistem informasi penjualan persediaan barang menggunakan Ms. Visual FoxPro 9 berbasis desktop[5].

\section{MetodePenelitian}

\subsection{Metode Analisa Critical Factor Succes}

Critical Factor Succes (CSF) ini merupakan metode Analisa yang mengembangkan strategi dalam sistem informasi dan juga melibatkan manajemen yang mampu memberikan kontribusi yang befektif untuk sebuah proses bisnis. Pada dasarnya metode Analisa Critical Factor Succes (CSF) ini terikat kuat dan sudah mengakar sangat kuat dalam sebuah proses bisnis yang memberikan solusi menjanjikan dalam manajemen bisnis bagi para manager dengan bisnis yang sudah beroriented sistem informasi dengan faktor-faktor penentu keberhasilan dan pencapaian bisnisnya.[6].

Pencapaian CSFs memberikan pelaksana dengan pemahaman yang lebih baik tentang bagaimana meningkatkan hasil proyek. Perusahaan[2].

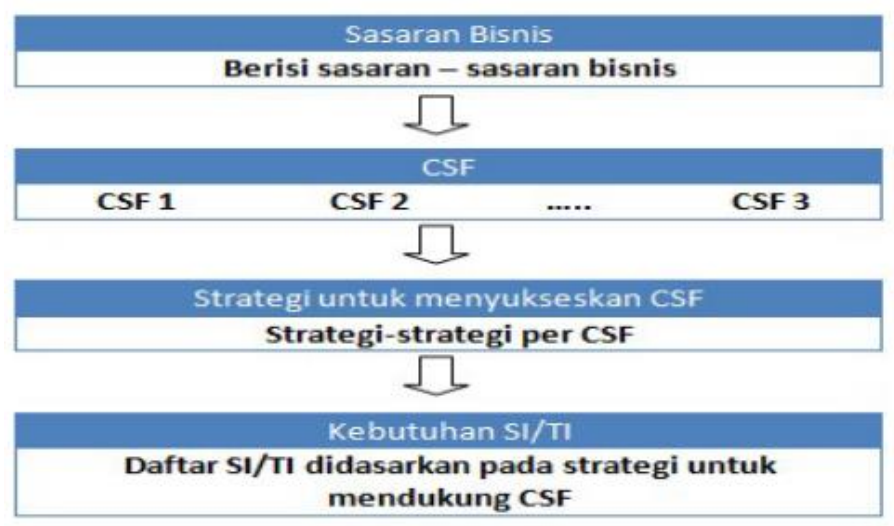

Gambar 1. Skema Proses Analisa CSF[7]

\subsection{Object Oriented Analysis Design (OOAD)}

Object Oriented Analysis Design (OOAD) adalah metode analisis yang memeriksa requirements dari sudut pandang kelas kelas dan objek yang ditemui dalam ruang lingkup permasalahan yang mengarahkan arsitektur software yang didasarkan pada manipulasi objek-objek sistem atau subsistem[8].

Perancangan OOAD (ObjectOriented Analysis Design) ini dalam tekniknya menggunakan UML karena unified modelling language ini dapat merancang diagram-diagram dalam analisi design berbasis objek[9].

\subsection{Metode Pengembangan SDLC (System Development Life Cycle)}

Metode pengembangan sistem SDLC yang digunakan ini terdiri dari 5 tahapan yaitu Perencanaan (Planning), Analisis (Analysis), Disiain (Design), Implementasi (Implementation) dan Pemeliharaan (Maintenance) ini merupakan tahapan penelitian yang digunakan penulis dalam membuat sistem transaksi dan persediaan barang.[10]:

\section{Hasil danPembahasan}

\subsection{Rancangan Sistem: Activity Diagram}

1. Use Case Diagram Admin dan Sales 


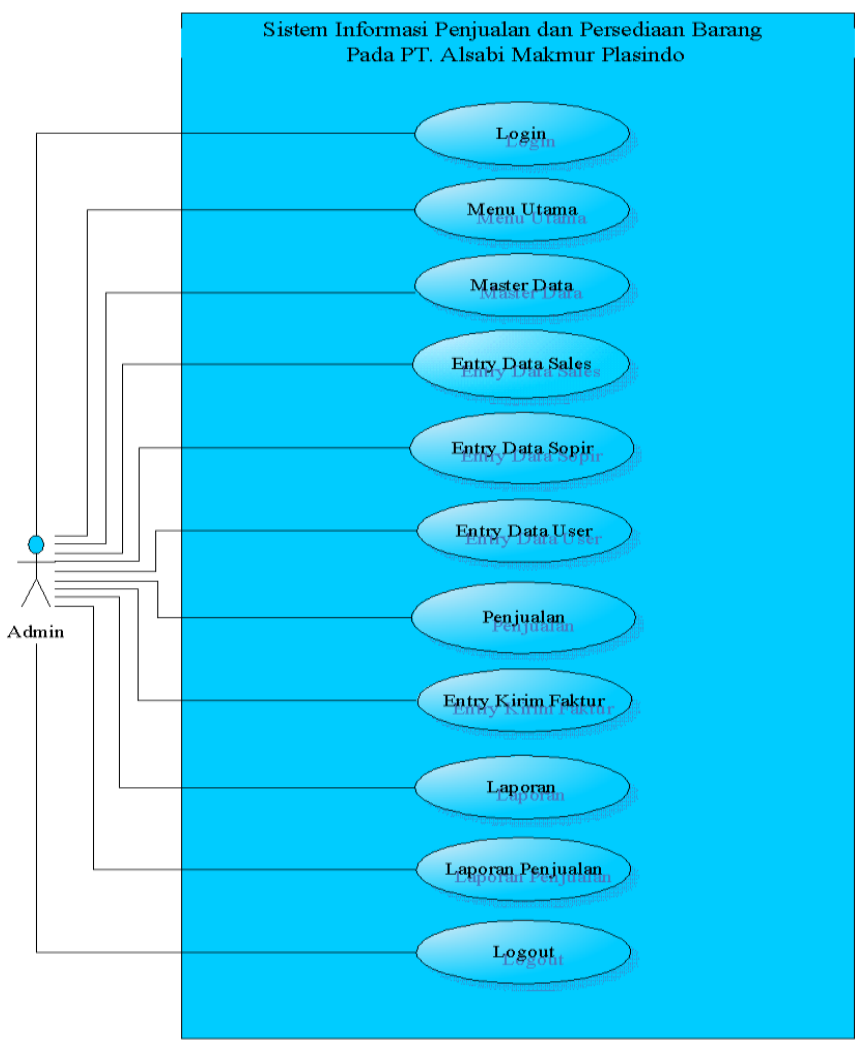

Gambar 2. Usecase Diagram Admin

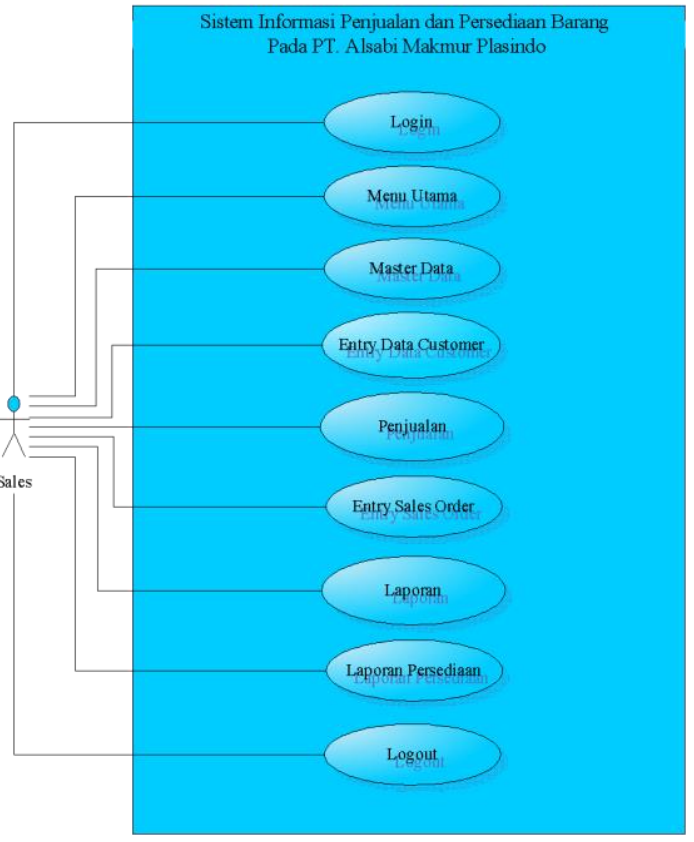

Gambar 3. Usecase Diagram Sales

Berdasarkan Gambar 2. Diatas yaitu Use Case Diagram Admin terdapat penjelasan sebagai berikut yaituterdiri dari 11 Usecase yang dilakukan oleh actor: Admin dengan 11 skenario sebagai berikut: Admin melakukan login, Admin mengelola data Menu Utama, Admin mengelola data Menu Master Data, Admin mengelola data Entry Data Sales, Admin mengelola data Entry Data Sopir, Admin mengelola data Entry Data User, Admin mengelola data Menu Penjualan, Admin mengelola data Entry Kirim Faktur, Admin mengelola data Menu Laporan, Admin mengelola data Laporan Penjualan dan melakukan Logout.

Berdasarkan Gambar 3 diatasada 9 alur yang dapat dijelaskan sebagai berikut yaitu terdiri dari 9 usecase yang dilakukan oleh actor: Sales dengan 9 skenario sebagai berikut: Sales melakukan login, Sales mengelola data Menu Utama, Sales mengelola data Menu Master Data, Sales mengelola data Entry Data Customer, Sales mengelola data Menu Penjualan, Sales mengelola data Entry Sales Order, Sales mengelola data Menu Laporan, Sales mengelola data Laporan Persediaan dan melakukan Logout.

\section{Activity Diagram Admin dan Sales}

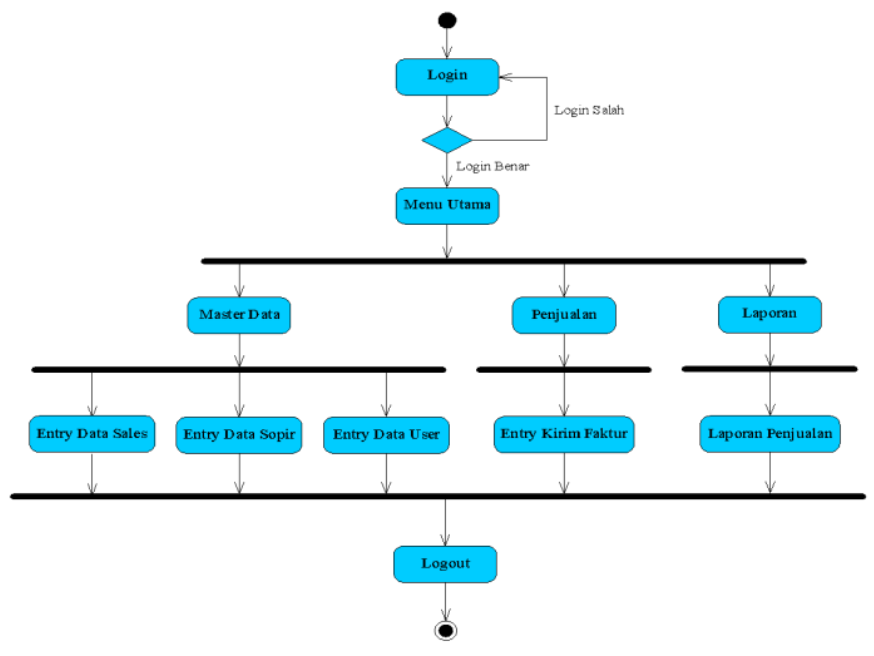

Gambar 4. Activity Diagram Admin

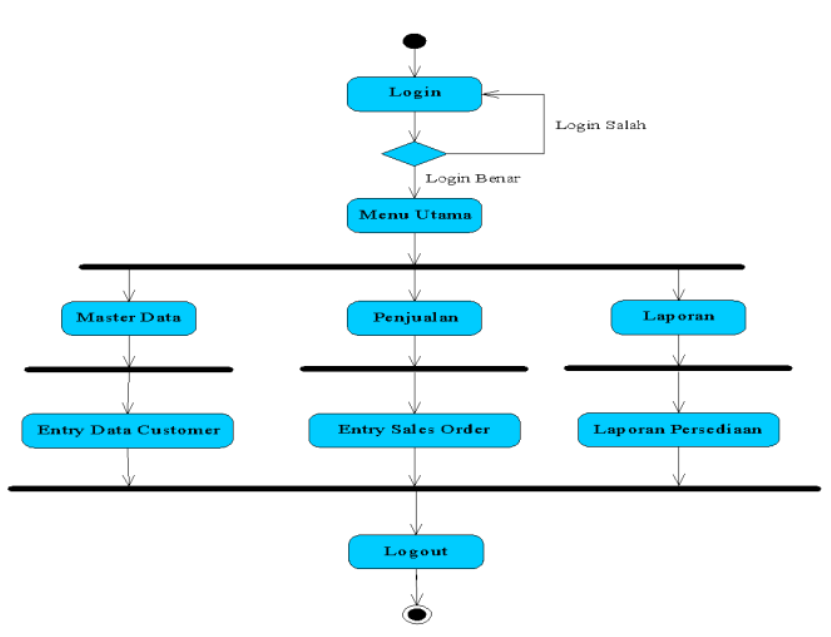

Gambar 5. Activity Diagram Sales

Berdasarkan Gambar 4 ActivityDiagram Sistem Admin terdapat 6 alur yang akan dijelaskan, yaitu sebagai berikut: 1 (satu) Intial node untuk mengawali objek, 11 (sebelas) Action, yang terdiri dari : Menampilkan Menu Login, 
Menampilkan Menu Utama, Menampilkan Menu Master Data, Menampilkan Form Entry Data Sales, Menampilkan Form Entry Data Sopir, Menampilkan Form Entry Data User, Menampilkan Menu Penjualan, Menampilkan Form Entry Kirim Faktur, Menampilkan Menu Laporan, Menampilkan Form Laporan Penjualan, Menampilkan Log Out, 1 (Satu) Decision node untuk pemilihan kondisi, 4 (Empat) Fork node untuk percabangan kegiatan, 1 (Satu) Join node untuk pengabungan kegiatan dan 1 (satu) Actifity final node untuk mengakhiri objek.

Berdasarkan Gambar 5. ActivityDiagram Sistem Sales terdapat 6 alur yang akan dijelaskan, yaitu sebagai berikut:1 (satu) Intial node untuk mengawali objek, 9 (sembilan) Action, yang terdiri dari : Menampilkan Menu Login, Menampilkan Menu Utama, Menampilkan Menu Master Data, Menampilkan Form Entry Data Customer, Menampilkan Menu Penjualan, Menampilkan Form Entry Sales Order, Menampilkan Menu Laporan, Menampilkan Form Laporan Persediaan, Menampilkan Log Out, 1 (Satu) Decision node untuk pemilihan kondisi, 4 (Empat) Fork node untuk percabangan kegiatan, 1 (Satu) Join node untuk pengabungan kegiatan dan 1 (satu) Actifity final node untuk mengakhiri objek.

\subsection{Perancangan Database: Class Diagram}

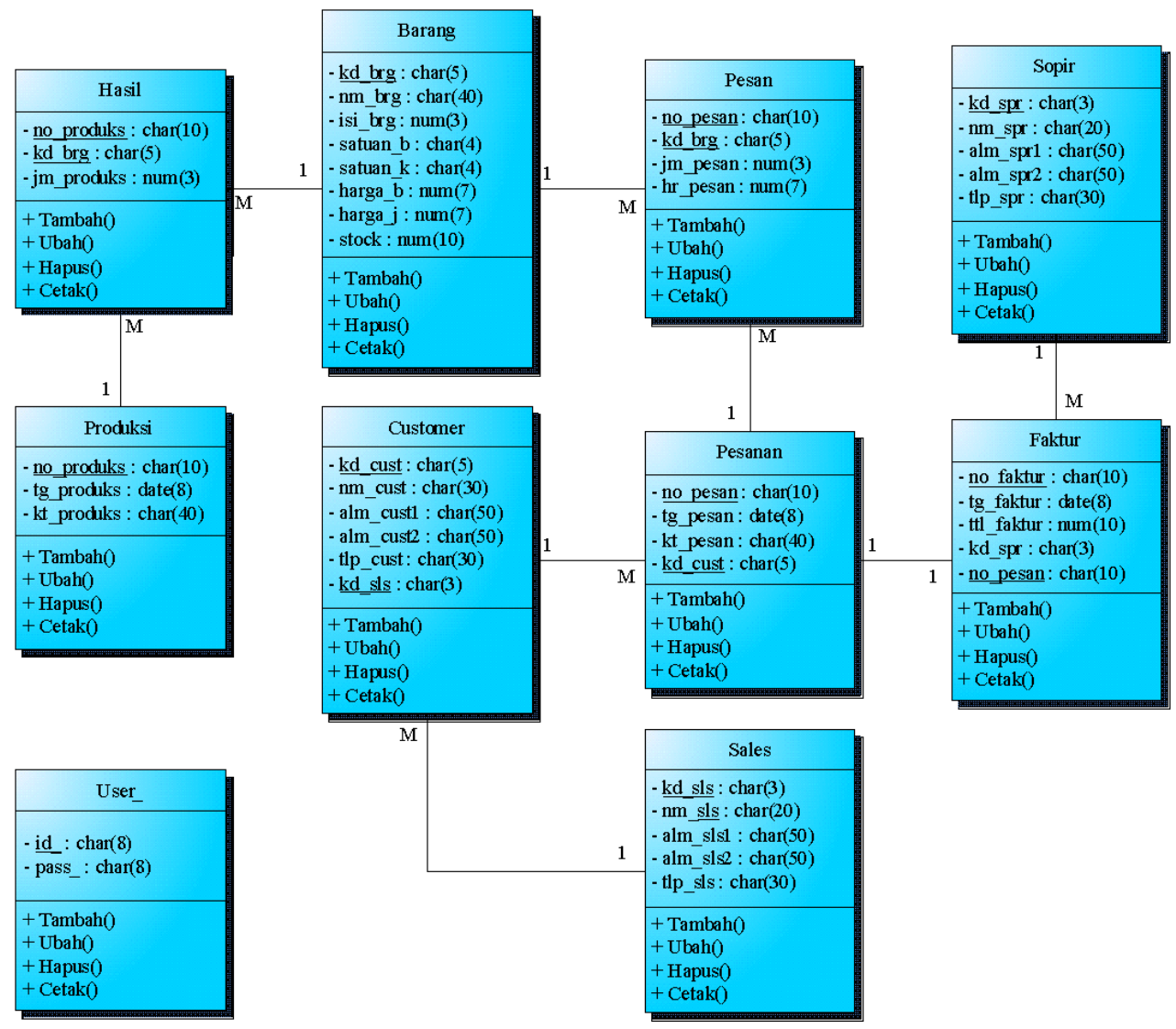

Gambar 6. Class Diagram

Berdasarkan gambar 6. Class Diagram diatas terdapat 10 tabel dalam database sistem penjualan dan persediaan barang yaitu: table produksi, table customer, table barang, table pesan, table pesanan, table sopir, table faktur, table hasil, table sales dan table user.

\subsection{Implementasi Sistem Penjualan dan Persediaan Barang \\ 1. Halaman Login Sistem}


ISSN: 2461-1409

Online ISSN: $2655-5298$

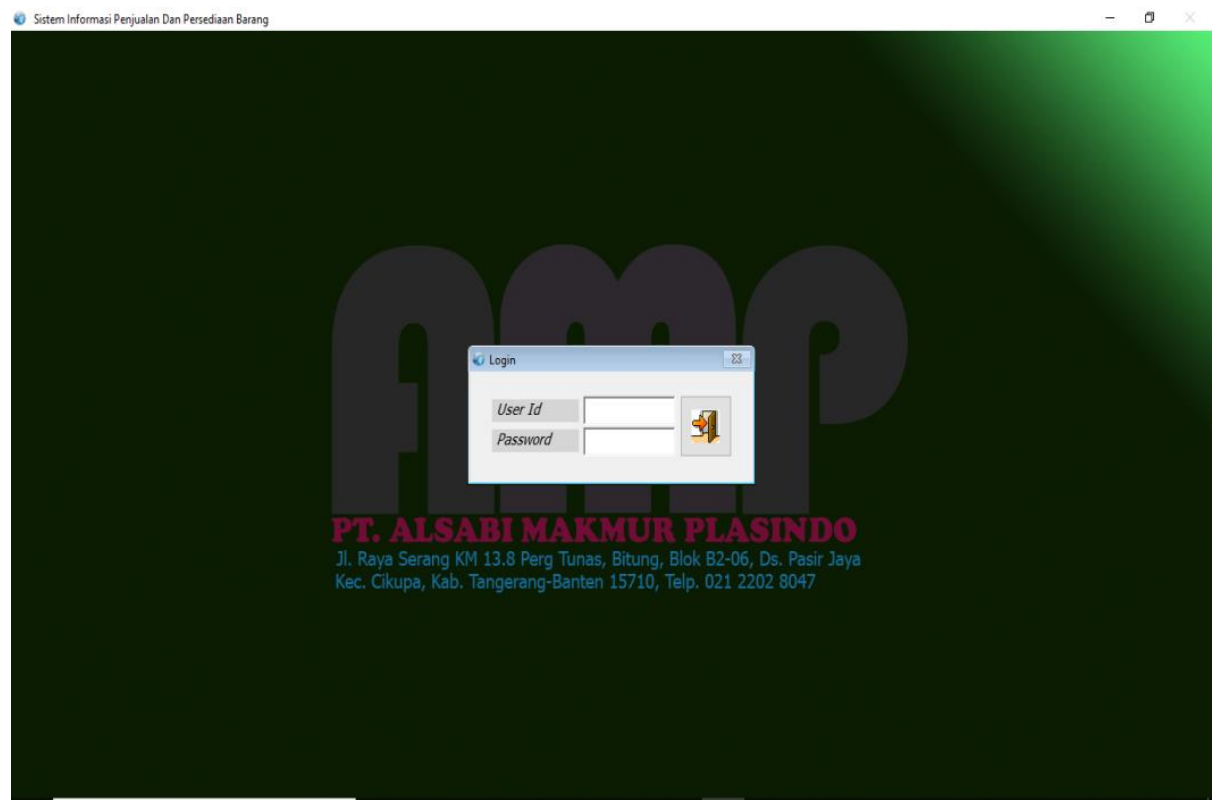

Gambar 7. Halaman Login Sistem

Berdasarkan gambar 7. Halman login sistem diatas dalam form login terdapat User Iddan Password.

2. Halaman Form Entry Barang

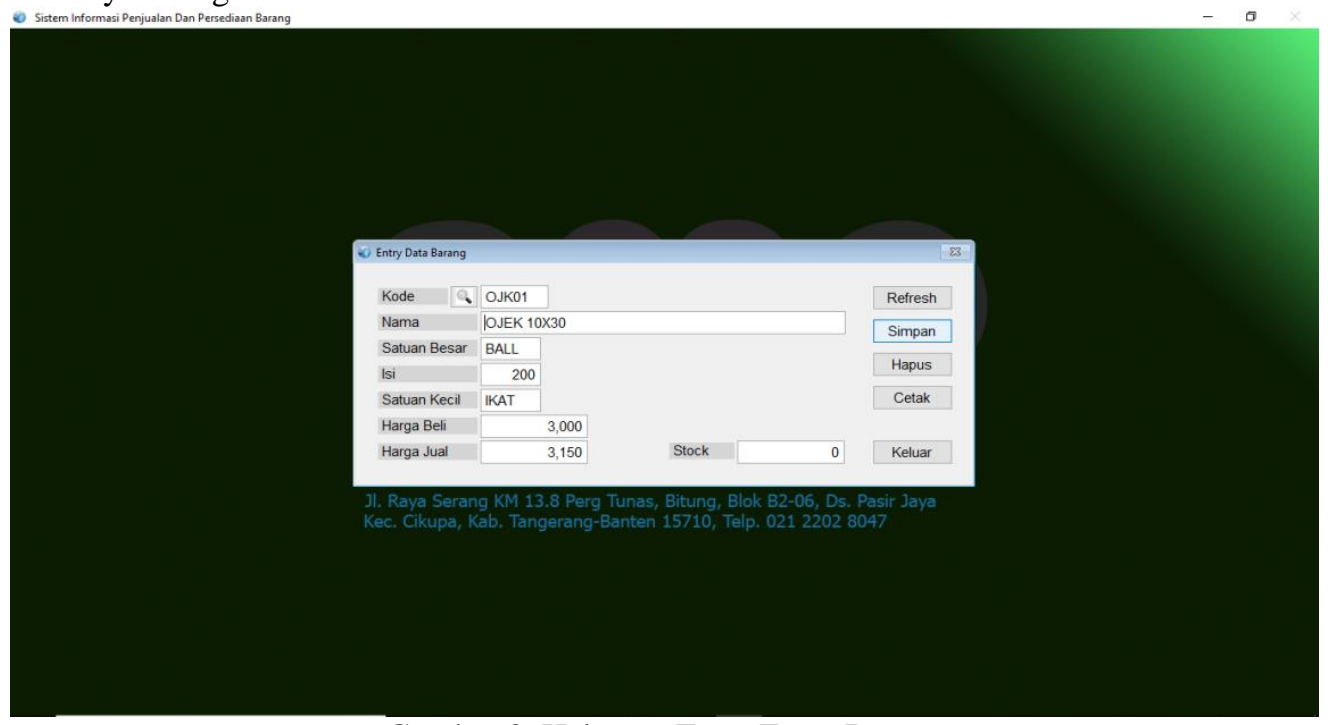

Gambar 8. Halaman Form Entry Barang

Berdasarkan gambar 8.halaman form entry data barang adalah untuk menginput data barang yang dilakukan pada bagian Produksi pada PT. Alsabi.

3. Halaman Form Entry Data Sales 


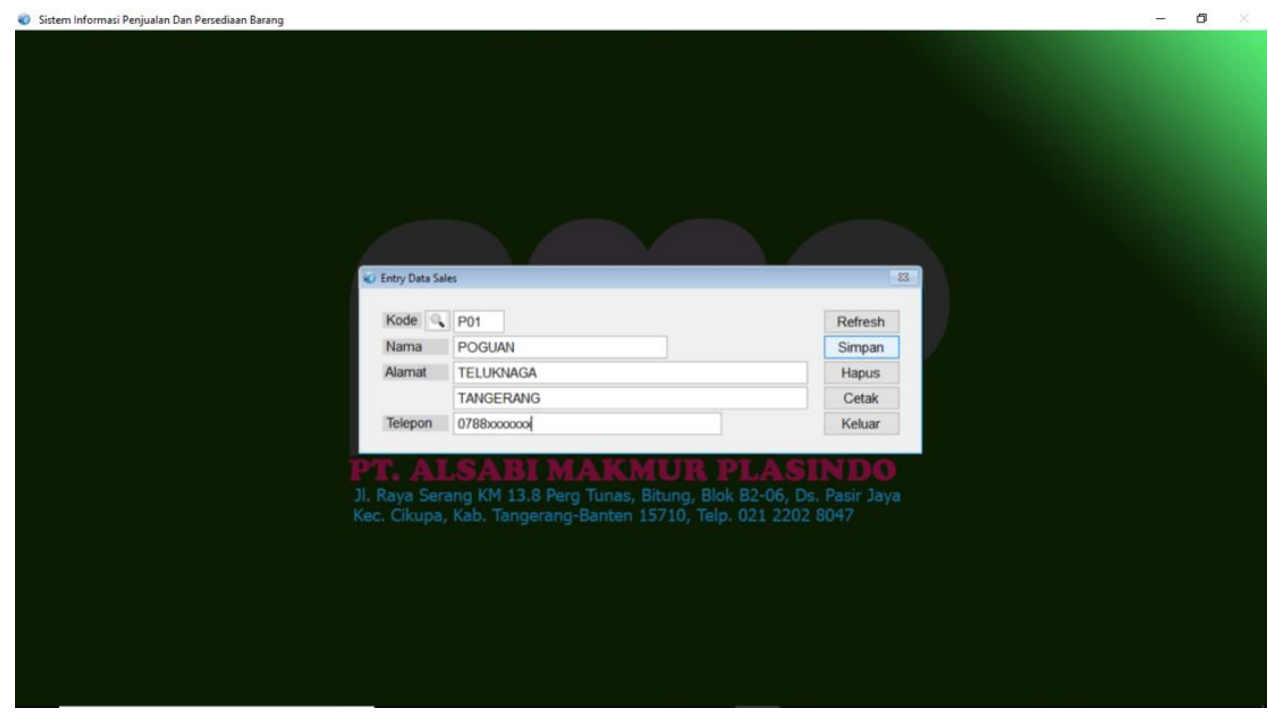

Gambar 9. Halaman Form Entry Data Sales

Berdasarkan gambar 9. Halaman form entry data sales diatas adalah untuk menginput data sales yang dilakukan oleh admin.

4. Halaman Form Entry Data Sopir

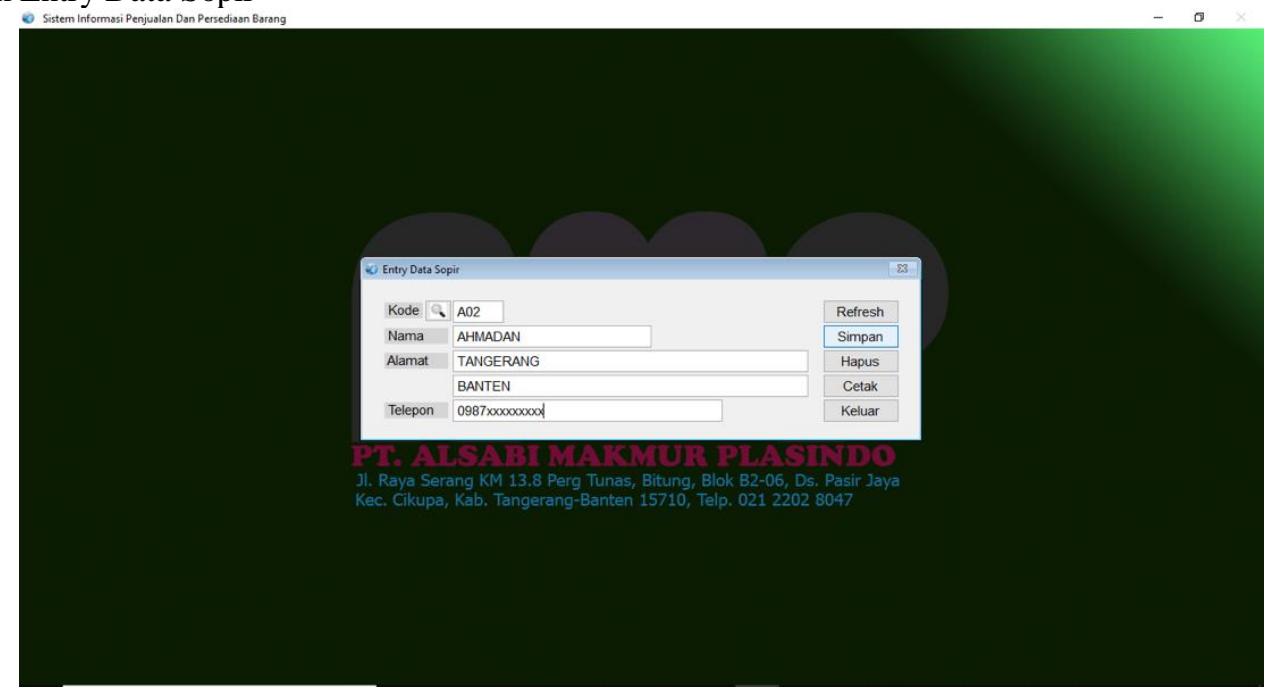

Gambar 10.Halaman Form Entry Data Sopir

Berdasarkan gambar 10. Halaman form entry data sopir diatas adalah untuk menginput data sopir yang dilakukan oleh admin.

5. Halaman Form Entry Data Customer 


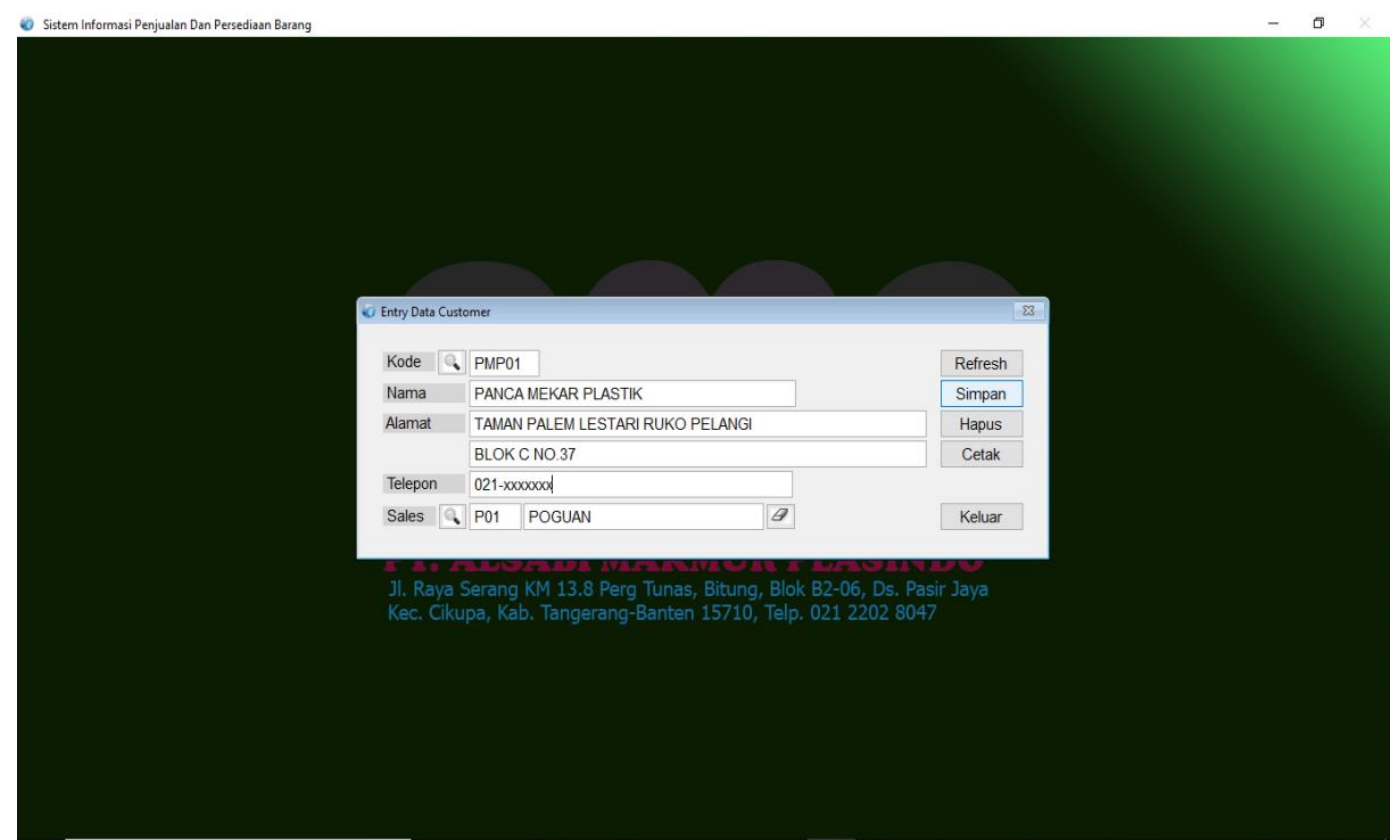

Gambar 11.Halaman Form Entry Data Customer

Berdasarkan gambar 11. Halaman form entry data customer diatas adalah untuk menginput data customer yang dilakukan oleh Sales.

6. Halaman Form Entry Hasil Produksi

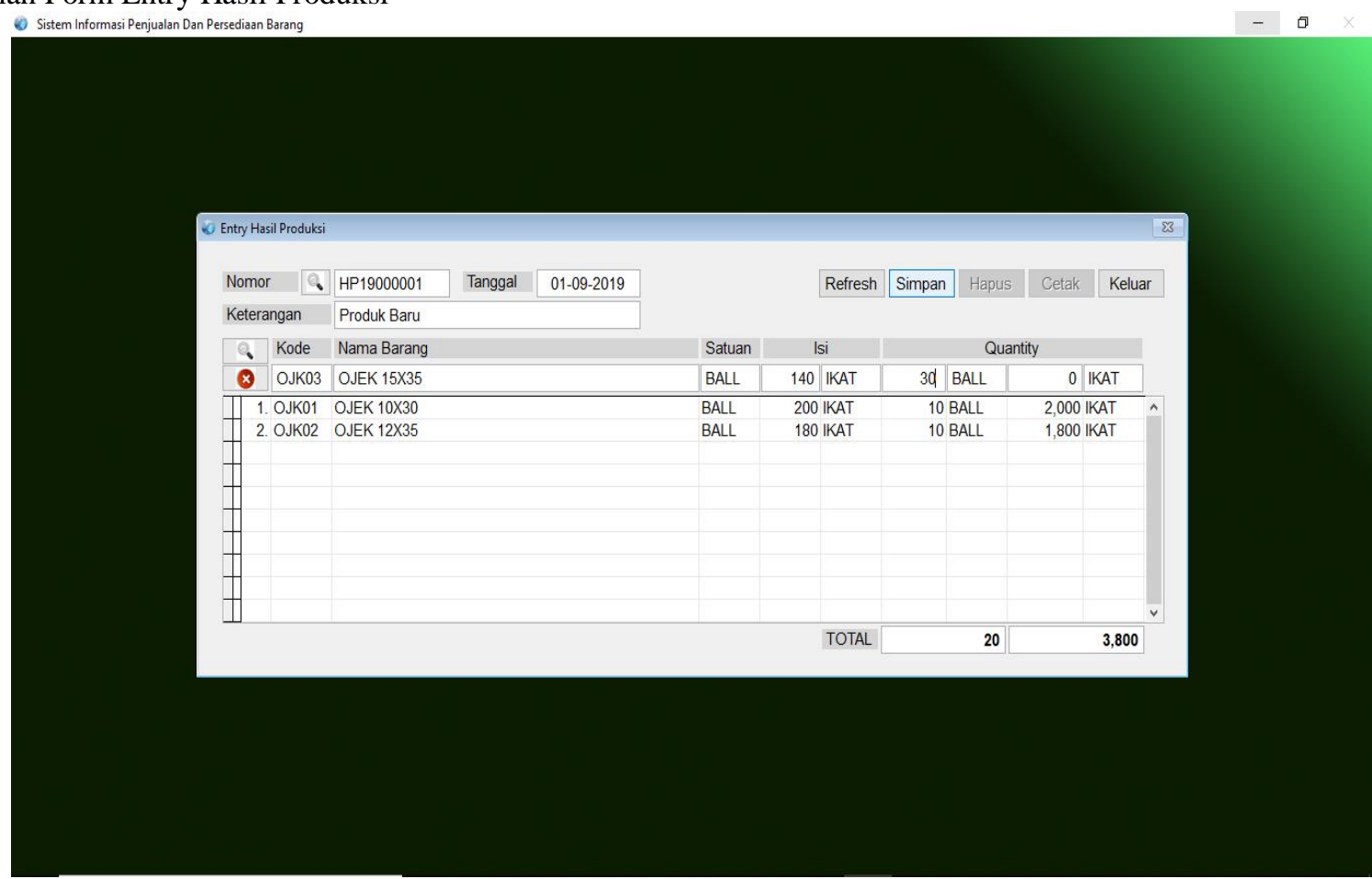

Gambar 12.Halaman Form Entry Hasil Produksi

Berdasarkan gambar 12.Halaman setelah Entry Data Barang yang dilakukan oleh Unit Produksi.

7. Halaman Form Entry Sales Order 
ISSN: 2461-1409

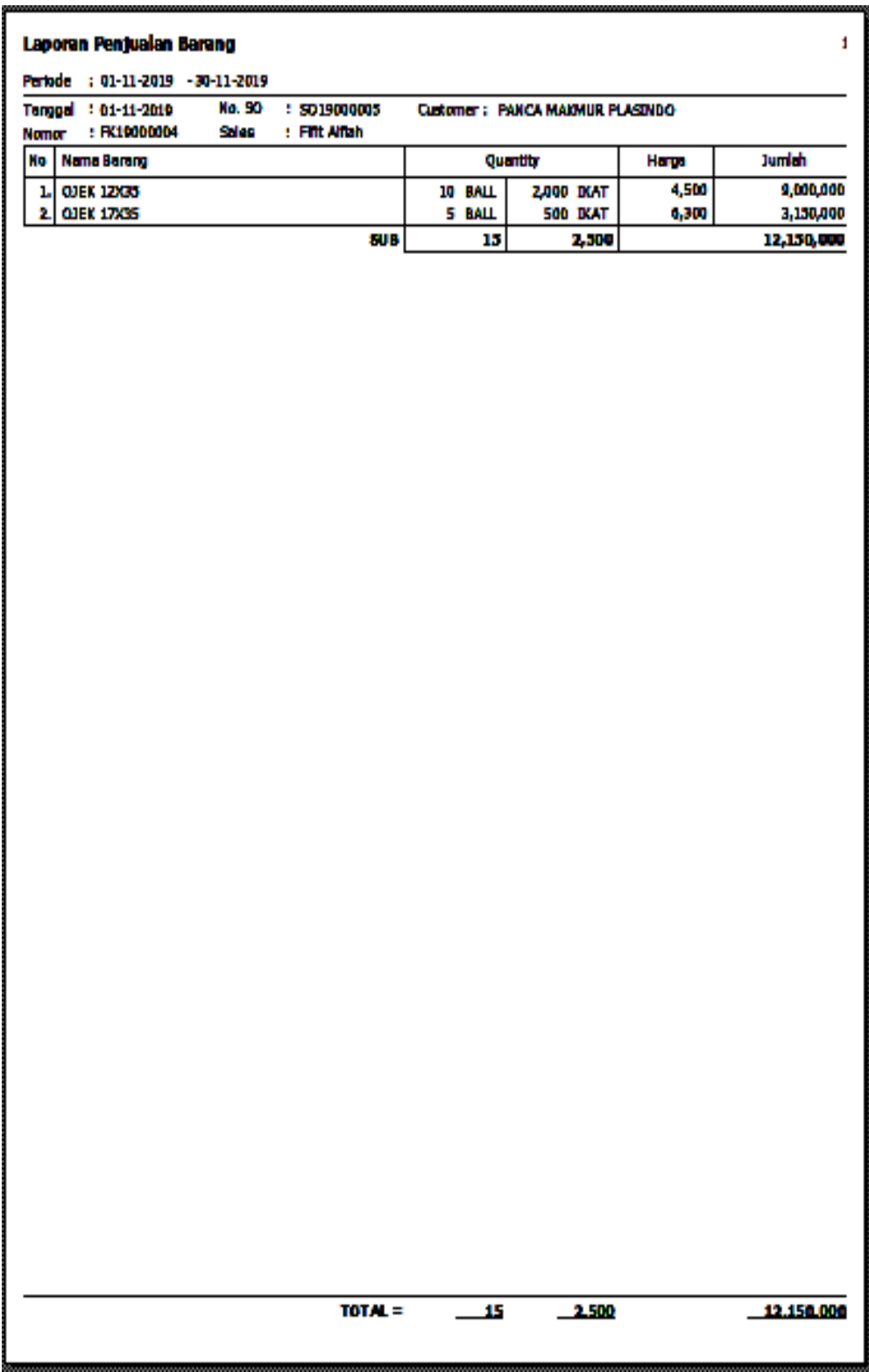

Gambar 15.Halaman Form Laporan Penjualan

Berdasarkan gambar 15. Halaman form laporan penjualan adalah untuk mencetak hasil laporan Admin.

10. Halaman Form Laporan Persediaan

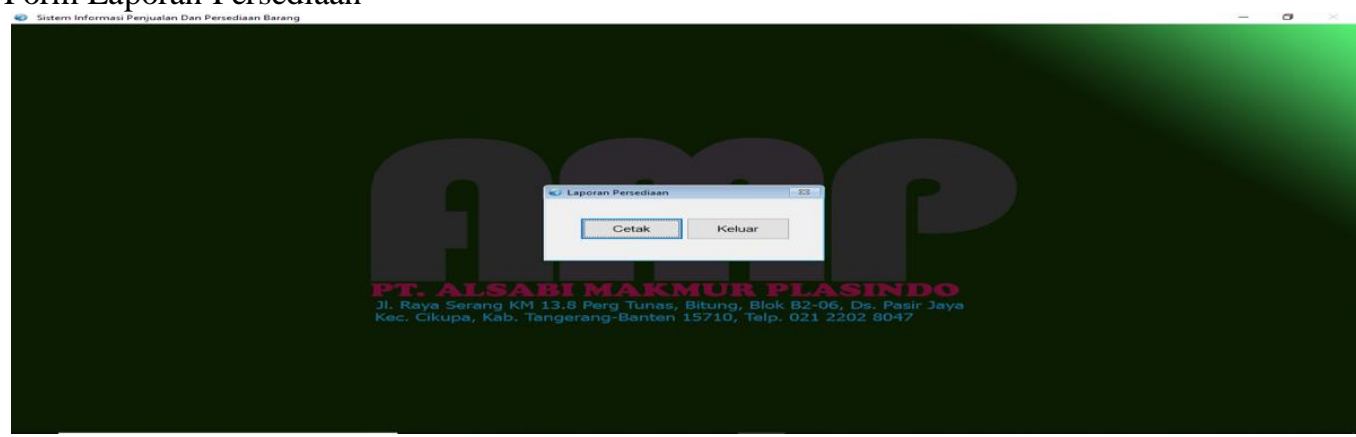




\begin{tabular}{|c|c|c|c|c|c|}
\hline \multicolumn{6}{|c|}{$\begin{array}{l}\text { Laporan Persedlean Barang } \\
\text { Tompd : 16-12-2019 }\end{array}$} \\
\hline$\mu_{0}$ & Kode & Hama & Is & \multicolumn{2}{|c|}{ Sock } \\
\hline & ouk01 & OWEK 10030 & $900 \mathrm{DK}$ DKT & x $\mathrm{BAL}$ & 18,000 DKAT \\
\hline 2. & 011K0 & OJEK 12835 & $200 \mathrm{DXAT}$ & $35 \mathrm{BNL}$ & $71,200 \mathrm{DXA}$ \\
\hline 3 & ojk四 & OWEK 15005 & $140 \mathrm{DKAT}$ & $\mathrm{O} \mathrm{BNL}$ & $O D K A T$ \\
\hline 4. & $01 \times 04$ & OWEK 17305 & $100 \mathrm{DXAT}$ & $5 \mathrm{BNL}$ & $5001 \times X A$ \\
\hline 5 & wKB02 & ADFEDD & 50 DKAT & $100 \mathrm{KG}$ & $3,000 \times D K A$ \\
\hline
\end{tabular}

Gambar 16.Halaman Form Laporan Persediaan

Berdasarkan gambar 16. Halaman form laporan persediaan diatas adalah untuk mencetak hasil laporansales.

\section{Kesimpulan}

Berdasarkan hasil dari penelitian program sistem informasi sudah selesai $100 \%$ dengan menyesuaikan faktor penentu kesuksesan penjualan dari PT. Alsabi Makmur Plasindo sehingga memudahkan perusahaan dalam proses penjualan dan menentukan persediaan barang berdasarkan penggunaan waktu data dapat diintegrasikan dengan cepat dan baik.

Penerapan metode analisa Critical Success Factor (CFS) inimempermudahperusahaan dalam mengambil keputusan yang dilakukan berdasarkan sistem penjualan dan persediaan barang dalam memproses pencatatan, penyimpanan dan pencarian data serta penyajian data penjualan barang.

Sistem Penjualan dan persediaan barang yang kembangkan berbasis desktop dengan menggunakan Ms. Visual FoxPro 9 dan database *.DBF untuk penyimpanan data. Diharapkan kedepannya agar mempermudah proses penjualan dan persediaan barang dapat membuat sistem dalam basis web maupun mobile. 


\section{DaftarPustaka}

[1] F. Alfiah, R. Sudarji, D. Taqiyyuddin, and A. Fatah, “Aplikasi Kriptografi Dengan Menggunakan Algoritma Elgamal Berbasis Java Desktop Pada Pt . Wahana Indo Trada Nissan Jatake," pp. 22-34.

[2] E. Dewi and P. Sari, "The Critical Success Factors Model For Implementation Of Enterprise Architecture In Pdam Tirta Raharja," no. September, pp. 1-11, 2018.

[3] N. Mashwama, C. Aigbavboa, and D. Thwala, "An Assessment Of The Critical Success factor For The Reduction Of Cost Of Poor Quality In Construction Projects In Swaziland .," Procedia Eng., vol. 196, no. June, pp. 447-453, 2017, doi: 10.1016/j.proeng.2017.07.223.

[4] F. Alfiah et al., "Perancangan Sistem E - Commerce Untuk Penjualan Pakaian Pada Toko A \& S," vol. 6, no. 1, pp. 70-81.

[5] G. Chandra, T. Willay, J. S. Informasi, and S. W. Dharma, "Persediaan Dan Penjualan Pada Pd Cahaya Metal Dengan Microsoft Visual Foxpro 9. 0."

[6] S. Kasus, P. T. Inkoprima, D. Tetap, and S. Eresha, "Perancangan Sistem Informasi Pengadaan Material Dengan Analisa Critical Sucsess Factor," vol. IX, no. 01, pp. 94-111, 2013.

[7] M. H. Prayitno, P. Studi, and S. Informasi, "Analisa Kebutuhan Sistem Informasi Dengan Menggunakan Analisis Value Change Dan Critical Success Factor Pada PT . LHE," vol. 3, no. 1, pp. 269-278, 2016.

[8] B. C. Neyfa and D. Tamara, "Perancangan Aplikasi E-Canteen Berbasis Android Dengan Menggunakan Metode Object Oriented Analysis \& Design ( Ooad ) 'E - Canteen' Android -Based Application Design Using Object Oriented Analysis \& Design Method tempat makan pada umumnya , dimana Area kantin kampus Politeknik Negeri Jakarta dipilih sebagai lokasi uji kasus . antara penjual dan pembeli . Tujuan ini adalah :," pp. 83-92, 2016.

[9] T. Pustaka, "E-Commerce Penjualan Berbasis Metode OOAD," vol. XV, no. April, pp. 1-5, 2018.

[10] A. Setiadi and F. Alfiah, "Sistem Penjualan Spare Part Toko Ajm Motor Menggunakan Ci Berbasis Arsitektur Mvc," Simetris J. Tek. Mesin, Elektro dan Ilmu Komput., vol. 7, no. 2, p. 575, 2016, doi: 10.24176/simet.v7i2.770. 